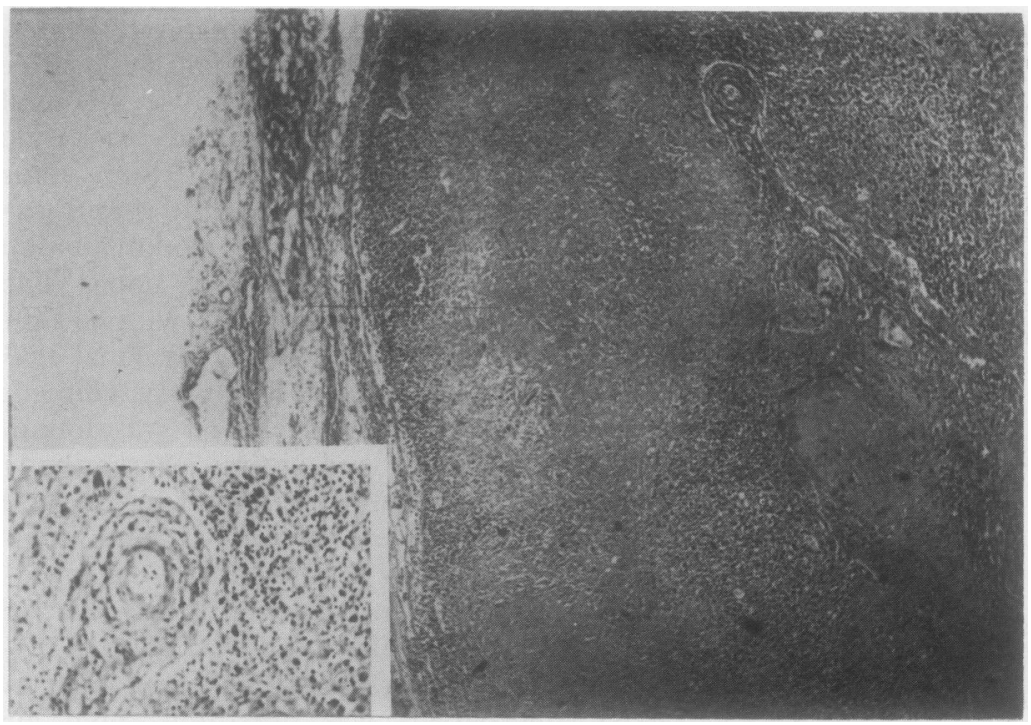

Figure 2 Hilar lymph node with vasculitis and necrotic areas surrounded by fibrous scar tissue and multinucleated giant cells, with a higher magnification inset giving a more detailed view of the vasculitis.

to exclude the diagnosis of Wegener's granulomatosis in favour of other conditions. Fauci $e t$ $a l,{ }^{2}$ in their series of 85 patients with 21 years' follow up, did not see hilar lymphadenopathy. We emphasise the hilar, mediastinal, diaphragmatic, and peripancreatic adenopathy found in our patient. Histologically, the lymph nodes showed both granulomas and necrotising vasculitis, indicating that the lymph node changes were due to Wegener's granulomatosis.

Single or multiple nodular masses, with or without cavitation, are the most common pulmonary manifestations in Wegener's granulomatosis. An atypical diffuse reticulonodular pattern was found in our patient. The endobronchial lesions in Wegener's granulomatosis are usually granulomas and secondary to pul- monary lesions. They occasionally obstruct the airway, and endoscopic removal is then necessary. ${ }^{3}$ Our patient had punched out ulcers in the larynx, trachea, and bronchi.

Gastrointestinal ulcers have been described rarely in Wegener's granulomatosis. None of the published reports ${ }^{4-5}$ describes ulcers throughout most of the digestive tract from lips to colon, as in our case.

Renal lesions are present in $83 \%$ of patients with Wegener's granulomatosis, ${ }^{6}$ focal and segmental glomerulonephritis being usual. The absence of glomerular lesions is characteristic of the limited form of the disease. In our case there were no renal lesions, although this limited form of Wegener's granulomatosis was nevertheless associated with severe multisystem disease leading to the patient's death.

We conclude that Wegener's granulomatosis should still be considered in the differential diagnosis when the chest radiograph is atypical, despite enlargement of hilar or mediastinal lymph nodes.

1 Cupps TR, Fauci AS. Granulomatosis de Wegener. In: Smith LH Jr, Smith LH, ed. The vasculitides. Philadelphia: Saunders, 1981:72-87.

2 Fauci AS, Haynes BF, Katz P, Wolff SM. Wegener's granulomatosis: prospective clinical and therapeutic experience with 85 patients for 21 years. Ann Intern Med 1983;98:76-85.

3 Cohen SR, Landing BH, King KK, Isaacs H. Wegener's granulomatosis causing laryngeal and tracheobronchial obstruction in an adolescent girl. Ann Otol Rhino Laryngol 1978;87:15-9.

4 Haworth SJ, Pusey CD. Severe intestinal involvement in Wegener's granulomatosis. Gut 1984;25:1296-300.

5 Sokol RJ, Farrel MK, McAdams AJ. An unusual presentation of Wegener's granulomatosis mimicking inflammatory bowel disease. Gastroenterology 1984;87:426-32.

6 Jenis EH, Lowenthal DT. Wegener's granulomatosis. In Jenis EH, Lowenthal DT, eds. Kidney biopsy interpretation. Philadelphia: Davis, 1987:193-202.

\section{Successful treatment of Bacillus cereus infection with ciprofloxacin}

\author{
A D Gascoigne, J Richards, K Gould, \\ G J Gibson
}

Department of A D Gascoigne

G J Gibson

\section{Department of}

Microbiology

J Richards

K Gould

Freeman Hospital,

Newcastle upon Tyne

NE7 7DN

Reprint requests to:

Dr Richards,

Public Health Laboratory,

West Norwich Hospital,

Norwich NR2 3TX.

Accepted 12 November 1990
Abstract

Bacillus cereus is rarely a pulmonary pathogen but may cause pneumonia in immunocompromised patients. A patient with bronchiectasis and no recognisable immunodeficiency had this organism isolated during two infective exacerbations, once from respiratory secretions and once by blood culture. Ciprofloxacin treatment was effective on both occasions.
Aerobic Gram positive spore bearing bacilli of the genus Bacillus are part of the normal flora of soil, dust, and other environmental sources. Although most Bacillus species isolated from clinical material can usually be considered irrelevant contaminants, $B$ cereus has a greater pathogenic potential. We report a case of recurrent pneumonia and bacteraemia due to Bacillus cereus that was treated with ciprofloxacin.

\section{Case report}

The patient, a 21 year old man, had had recurrent chest infections from childhood as a result of bronchiectasis of unknown cause. There was no history of whooping cough or other important early childhood illness. At the age of 12 years he had been extensively investigated and serum electrophoresis findings, immunoglobulin concentrations, ciliary function, and sweat test results were all normal. The diagnosis was based on the history and 
clinical and radiographic findings, a computed tomogram of the thorax showing lower lobe bilateral bronchiectasis, which was later confirmed when the patient underwent heart-lung transplantation.

At the time of referral he had severe generalised airways obstruction and chronic respiratory failure with hypoxaemia and carbon dioxide retention. He was admitted with fever, rigors, and increasing cough. On examination he was toxic with signs of left lower lobe consolidation, which was confirmed by chest radiography. He had severe acute on chronic respiratory failure and shortly after admission intermittent positive pressure ventilation was started. Treatment had been started 24 hours earlier with intravenous azlocillin and gentamicin, despite which there was clinical deterioration. Bronchoalveolar lavage was performed and while the culture results were awaited the antibiotic treatment was changed empirically to intravenous ciprofloxacin. This resulted in rapid clinical improvement; he was extubated after $\mathbf{4 8}$ hours and discharged from hospital seven days later.

The patient was readmitted four weeks later with a two week history of lethargy and malaise associated with an increase in sputum volume. He had low grade fever with further signs of left lower lobe pneumonia and cor pulmonale. On this occasion there was clinical and radiographic evidence of consolidation in the left lower lobe. Again, he showed substantial clinical improvement within 48 hours of starting treatment with oral ciprofloxacin.

Microbiological investigations At the first admission a $\beta$ haemolytic spore bearing organism, later identified as Bacillus cereus, was isolated as the predominant organism from sputum and specimens obtained by bronchoalveolar lavage. At the second admission the same organism was recovered from blood cultures. No other potential pathogen was isolated on either occasion or from sputum between the two episodes. Serological examination of paired specimens showed no evidence of infection by atypical pathogens after either event. Serum immunoglobulin concentrations at the time of admission were normal (IgG $14.4 \mathrm{~g} / 1, \operatorname{IgM} 1.07 \mathrm{~g} / 1$, IgA 3.62 $\mathrm{g} / \mathrm{l})$. The organism was confirmed as $B$ cereus by the Food Hygiene Laboratory, Central Public Health Laboratory, where it was noted to produce a large amount of toxin. The bacillus was sensitive to penicillin (minimum inhibitory concentration (MIC) $<0.06 \mathrm{mg} / \mathrm{l}$ ), erythromycin (MIC <0.25 mg/l), gentamicin $($ MIC $<0.12 \mathrm{mg} / \mathrm{l})$, ciprofloxacin (MIC $<0.06$ $\mathrm{mg} / \mathrm{l}$ ), and, unusually for a Gram positive organism, aztreonam (MIC $<0.1 \mathrm{mg} / \mathrm{l})$. The organism was not a $\beta$ lactamase producer.

After the two episodes described here the patient required further hospital admissions for infective exacerbations. No further isolates of $B$ cereus were made, Haemophilus influenzae and Pneumococcus sp each being isolated on several occasions. The patient underwent successful heart-lung transplantation six months after the second infective exacerbation we described.

\section{Discussion}

Bacillus cereus is an aerobic spore forming organism found widely in the environment. Some strains produce an exotoxin, which activates adenylcyclase and may therefore have enterotoxic activity, and which if injected into skin can cause a localised increase in vascular permeability and necrosis. Most strains produce $\beta$ lactamase. Although a well recognised cause of gastroenteritis, ${ }^{1}$ systemic infections due to $B$ cereus are uncommon. ${ }^{2}$ Localised infections sometimes occur, particularly in the eye, ${ }^{3}$ and in dirty wounds. ${ }^{4}$ Pulmonary infection is very rare, usually a severe necrotising pneumonia in immunocompromised patients that is nearly always fatal. ${ }^{5}$

As Bacillus spp are common laboratory contaminants the initial isolation of such an organism from any source presents a therapeutic dilemma. Our case suggests that $B$ cereus may be a pathogen in an apparently immunocompetent patient, even when isolated from an unusual site. The apparent failure of conventional antibiotic treatment at therapeutic doses (peak gentamicin levels $8 \mathrm{mg} / \mathrm{l}$ ), despite "sensitive" MICs, could be explained by inadequate tissue concentrations; ciprofloxacin may have been effective because of its good penetration of respiratory secretions. ${ }^{6}$ Recurrent infections, which have not been described before, could be due to the persistence of $B$ cereus spores.

We wish to thank the Central Public Health Laboratory for their assistance with this case.

1 Gilbert RJ, Turnbull PCB, Parry JM, Kramer JM. Bacillus cereus and other Bacillus species: their part in food poisoning and other clinical infections. In: Berkeley RCW, Goodfellow N, eds. The aerobic endospore-forming bacteria: classification and identification. London: Academic Press, 1981:297-314.

2 Anonymous. Bacillus cereus as a systemic pathogen. Lancet 1983;ii: 1469.

3 Shamsuddin D, Tuazon CU, Levy C, Curtin J. Bacillus cereus panophthalmitis: source of the organism. Rev Infect Dis 1982;4:97-103.

4 Dryden MS, Kramer JM. Toxigenic Bacillus cereus as a cause of wound infections in the tropics. $J$ Infect 1987; 15:207-12.

5 Bekemyer WB, Zimmerman GA. Life threatening complications associated with $B$ cereus pneumonia. Am Rev Respir Dis 1985;131:466-9.

6 Berre J, Thys JP, Husson N, Klasterby J. Penetration of ciprofloxacin and bactericidal activity in bronchial secretions [abstract]. In: Program and abstracts of the 25th Interscience Conference on Antimicrobial Agents and Chemotherapy. Minneapolis, 1985:277. 